\title{
Effectiveness of Various Tongue Cleaning Aids in the Reduction of Tongue Coating and Bacterial Load: A Comparative Clinical Study
}

\author{
Vartul Dwivedi ${ }^{1}$, Nilesh A Torwane ${ }^{2}$, Sanjeev Tyagi ${ }^{3}$, Satish Maran ${ }^{4}$
}

\begin{abstract}
Aim: To remove tongue biofilm and improve breath odor, specific instruments (tongue scrapers) or toothbrushes are used.

Materials and methods: This study compared the effectiveness of a manual toothbrush that has a tongue scraper on the back of its head and two commercially available tongue scrapers in reducing the tongue coating and aerobic and anaerobic microbiota of the tongue dorsum. A randomized, negative controlled, double-blind, parallel design study for three different treatment interventions was conducted.

Results: All tongue cleaners showed a significant reduction in Winkle's tongue coating scores with significant values of reduction $(p<0.001)$ of the anaerobic bacterial count with plastic and metal tongue scraper when compared to brush scrapper.

Conclusion: There was an effective reduction of bacterial load on tongue dorsum with the use of tongue cleaners, with maximum load reduction by using plastic tongue cleaners.

Clinical significance: The results of the present study may be helpful for the dentists while prescribing tongue cleaners to their patients in their clinical practice.
\end{abstract}

Keywords: Biofilm, Brush scraper, Micro bacteria, Tongue, Tongue scraper

The Journal of Contemporary Dental Practice (2019): 10.5005/jp-journals-10024-2536

\section{INTRODUCTION}

t is estimated that approximately $85 \%$ of all halitosis cases have their origin in the mouth; of these, $50 \%$ are caused by tongue residue. The tongue which is also considered as a gateway to all important digestive systems is a home of a number of bacteria that cause several health hazards. Human oral cavity has been identified with more than 700 species of bacteria. Whereas an average individual may carry 100-200 species of bacteria; this shows vast heterogeneity between the individuals. ${ }^{1}$ The dorsum of the tongue carries a distinctive ecological niche by providing a large surface area which helps to promote the acquisition of microorganisms along with food debris, saliva, and degenerated epithelial cells which can be responsible for metabolism and growth of these entities. Further, the bacterial metabolism may break into the production of volatile molecules such as short-chain organic acids, volatile sulfur, diamine and phenyl derivatives. A tongue cleaner (also called a tongue scraper or tongue brush) is an oral hygiene device designed to clean the bacterial build-up, food debris, fungi, and dead cells from the surface of the tongue.

According to Tonzetich, ${ }^{2}$ bad breath is prevalent (at least occasionally) in more than $50 \%$ adults. According to some investigators; the majority of the adult populations have experienced a bad breath at least once in a while, especially after waking or after eating a specific type of food. Some of the researchers in their study have also found that at least $50 \%$ of their sampled population was suffering from lasting bad breath and that for nearly half of the population had a severe chronic problem of bad breath. Also, it has been found that the prevalence of oral malador in the USA is very much high and the problem is only lagging behind dental caries and periodontal diseases. ${ }^{3}$

Boever and Loesche ${ }^{4}$ indicated that the proteolytic, anaerobic flora residing on the tongue plays an essential role in the development of halitosis.

Oral malodor is an identifiable condition which needs professional attention. Apprehensions have been raised against commercial "breath clinics" and substances that deficit scientific credentials. ${ }^{5}$ On

\begin{abstract}
1,3 Department of Conservative Dentistry and Endodontics, People's Dental Academy, Bhopal, Madhya Pradesh, India

${ }^{2}$ Department of Public Health Dentistry, College of Dental Sciences, Bhavnagar, Gujarat, India

${ }^{4}$ Department of Pediatric and Preventive Dentistry, People's Dental Academy, Bhopal, Madhya Pradesh, India
\end{abstract}

Corresponding Author: Nilesh A Torwane, Department of Public Health Dentistry, College of Dental Sciences, Bhavnagar, Gujrat, India, e-mail: nealdip@gmail.com

How to cite his article: Dwivedi V, Torwane NA, Tyagi S, Maran S. Effectiveness of Various Tongue Cleaning Aids in the reduction of Tongue Coating and Bacterial Load: A Comparative Clinical Study. J Contemp Dent Pract 2019;20(4):444-448.

Source of support: Nil

Conflict of interest: None

the other way, there is urgency for dental professionals to update and consolidate the recent knowledge in this field. This will provide equitable scientific information to patients and will enhance the education of dental professionals in this area.

Therefore, the present comparative clinical study was conducted to evaluate the mechanical effectiveness of three tongue cleaning aids in reducing the extent of tongue coating and bacterial load of the tongue.

\section{Materials and methods}

\section{Study Setting}

The present study was conducted in the Department of Public Health Dentistry of a dental institute.

\section{Study Duration}

The present study was conducted for a period of 15 days.

Ethical clearance and informed consent: Present randomized, double-blind, parallel designed study was conducted after approval

(o) The Author(s). 2019 Open Access This article is distributed under the terms of the Creative Commons Attribution 4.0 International License (https://creativecommons. org/licenses/by-nc/4.0/), which permits unrestricted use, distribution, and non-commercial reproduction in any medium, provided you give appropriate credit to the original author(s) and the source, provide a link to the Creative Commons license, and indicate if changes were made. The Creative Commons Public Domain Dedication waiver (http://creativecommons.org/publicdomain/zero/1.0/) applies to the data made available in this article, unless otherwise stated. 
by the ethical committee of a dental institute. Also, before the commencement of study; complete study protocol was explained and informed consent was obtained from each study participant.

\section{Sample Size}

A total of 20 healthy adult male and female dental assistants of a dental college were enrolled in the study.

- Selection criteria:The eligibility criteria for the willing participants were decided before the study. The eligibility criteria included that all subjects must have at least 20 natural teeth and no gagging reflex. Subjects with severe abnormal tongue defects like fissured and geographic tongue, subjects having pierced tongue or with any other abnormality which might interfere with tongue sampling procedures were excluded from the study. Subjects are instructed to avoid the use of antimicrobial mouthwashes, peroxide tooth bleaching products, or any systemic antibiotics during the study period. Also, the subjects were asked to avoid elective dentistry and prophylaxis during the trial and not to use any non-study oral care products for the duration of the study.

- Study procedure and intervention: The present study was investigated by a single examiner. Initially, all the study participants carried out unsupervised acclimatization period wherein they set aside their normal oral hygiene routine and were asked to brush for two minutes twice daily with a manual soft toothbrush and paste provided by the examiner. Subjects were instructed to abstain from tongue cleaning for the entire acclimatization period. To avoid confounder's bias, subjects were cautioned to abstained from the use of oral hygiene product and to carry out any personal habit (i.e. eating, drinking, performing oral hygiene, smoking, drinking alcohol or using breath mints, lozenges, or chewing gum) after 10:00 pm prior to the evening preceding their baseline visit.

Before the onset of the study the examiner was calibrated and kappa value was calculated for the recording of the index and professional training from a microbiologist was obtained in order to take cultural swabs of the subjects. On the 7th day, Winkles tongue coating index (WTCl) and culture swab samples were collected for all the subjects selected for the study. After the collection of the samples the subjects were demonstrated the proper way of tongue cleaning with the aid provided to them on that particular day, and then the subjects were asked to clean their teeth and tongue with the intervention aid provided by the examiner (Fig. 1). Following the tongue cleaning procedure the post-intervention records of Winkles Tongue Coating Index and culture swabs of the tongue dorsum were recorded. ${ }^{6}$

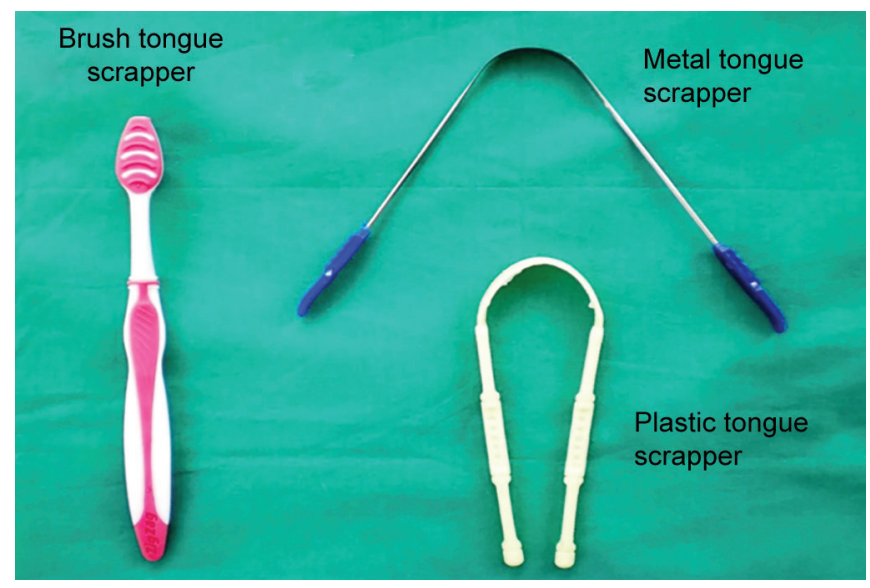

Fig. 1: Tongue cleaning aids used
Following the intervention and sample taking, there was a period of washout for 48 hours in which the subjects were asked only to brush their teeth normally twice daily and visit the Department of Public Health again for recording baseline and post-intervention with the new tongue cleaning aid. Similarly after every 48 hours samples and index was recorded for baseline and post-intervention. This cycle continued till about two weeks until all pre and post-intervention scores and samples were recorded for all subjects with all three tongue cleaning aids (Fig. 2).

\section{Winkle Tongue Coating Index ${ }^{7}$}

To record the tongue coating, the dorsal surface of the tongue was further divided into six regions ( 3 anterior and 3 posterior) anterior to sulcus terminalis.

Tongue coating was assessed in each sextant as:

- $0=$ No coating,

- 1 = Light coating,

- 2 = Severe coating.

The WTCl was obtained by addition of all 6 scores, range $0-12$.

- $0-4=$ Mild coating

- $4.1-8=$ Moderate coating

- $8.1-12=$ Severe coating

\section{Microbiological Tests}

To record the bacterial load baseline and post-intervention microbiological samples were collected from the tongue dorsum anterior to sulcus terminalis. The microbial samples from the dorsum of the tongue were obtained by wiping a sterile cotton swab. The cotton swabs were transferred and stored in screwcapped vials, containing $3 \mathrm{~mL}$ RTF. The collected swabs were then taken to the microbiological lab for further analysis. For all the samples; dilutions $10^{-1}-10^{-5}$ were plated by means of a spiral platter onto non-selective blood agar plates. After 24 hours of aerobic and 48 hours of anaerobic culturing at $37^{\circ} \mathrm{C}$ in the incubator, then all the aerobic and anaerobic colony forming units (CFU/mL) were counted for the pre-intervention and post-intervention samples.

\section{Questionnaire}

A close-ended questionnaire was framed in order to do the subjective analysis of each aid (Fig. 2). Each time the subjects used a particular tongue cleaning aid they were instructed to provide their response to a questionnaire pertaining to any possible sideeffects or discomfort of the cleaning aids. At the end of the study; the subjects were also asked to record their experience related to usage of a tongue cleaner.

\section{Statistical Analysis}

Statistical analysis was carried out using SPSS 14.0 software. The mean results were calculated for each aid and then compared within

QI: Have you experienced any reduction in the level of bad breath after using the tongue cleaner?
a. Yes
b. No

Q2: Have you experienced any improvement in taste after using the tongue cleaner?
a. Yes
b. No

Q3: Have you experienced any gagging reflex while using the tongue cleaner?
a. Yes
b. No

Q4: How was your experience about usage of a tongue cleaner? a. Comfortable b. Uncomfortable

Fig. 2: Questionnaire used in the study 
(baseline and post intervention) and between the three different aids using the student t-test. $p<0.05$ was considered statistically significant.

\section{Results}

The results of the study reported no dropouts with the mean age for the male and the female participants as $24.18 \pm 3.38$ years and $23.44 \pm 3.97$ years respectively (Table 1 ). All three cleaning aids reported a highly significant scores of reduction although maximum mean reduction of tongue coating was obtained with the plastic tongue scrapper, i.e., mean reduction 2.80 (Table 2).

The mean values of pre and post-intervention scores of the aerobic bacterial count was compared for the three different tongue cleaning aids used, all aid showed a significant reduction. Although the mean reduction scores was highly significant $(p<0.001)$ amongst those who cleaned their tongue with the plastic tongue scraper (Table 3). On comparing the mean value of pre, postintervention and reduction scores of the anaerobic bacterial count only plastic and metal tongue scraper showed significant values of reduction $(p<0.001)$ whereas, the mean reduction scores obtained by the brush scrapper were not found to be significant (Table 4). The mean reduction of aerobic and anaerobic bacterial count when

Table 1: Age and gender wise distribution of study subjects

\begin{tabular}{|c|c|c|c|}
\hline \multirow{2}{*}{$\begin{array}{l}\text { Age group } \\
\text { (in years) }\end{array}$} & \multicolumn{2}{|c|}{ Gender } & \multirow[b]{2}{*}{ Total } \\
\hline & Male & Female & \\
\hline$<23$ & $6(30.00)$ & $7(35.00)$ & $13(65.00)$ \\
\hline$>23$ & $5(25.00)$ & $2(10.00)$ & $7(35.00)$ \\
\hline \multirow[t]{2}{*}{ Total } & $11(55.00)$ & $9(45.00)$ & $20(100.00)$ \\
\hline & $\begin{array}{l}\text { Mean age } \\
\text { (Male) } \\
24.18+3.38\end{array}$ & $\begin{array}{l}\text { Mean age } \\
\text { (Female) } \\
23.44+3.97\end{array}$ & \\
\hline
\end{tabular}

was compared between the three intervention products used in the study, a highly significant value was obtained when the mean reduction of bacterial count of brush scrapper was compared to plastic scrapper. Mean reduction of bacterial load with plastic scrapper in comparison to the others showed significant reduction (Tables 5 and 5A).

After each intervention the subjects were assessed on the usage and effects of the products provided to the subjects, according to which $80 \%$ of the study subjects experienced reduction in halitosis with brush and plastic tongue scrapper compared to metal tongue scrapper. About $50 \%$ of the subjects reported change in taste alteration after usage of plastic tongue scrapper. More than three fourth of the subjects using plastic tongue scrapper reported increased gagging reflex and discomfort level. Overall, in terms of preference, it was observed that brush scrapper was highly preferred by the study subjects compared to plastic and metal tongue scraper as it greatly reduced halitosis level with minimum discomfort (Table 6).

The data of this study indicates that tooth brushing alone does not improve significantly the breath odor of the participants. Tongue cleaning notably is required in order to minimize the level of tongue coating and bacterial load. Although the patient's compliance with plastic tongue cleaner was not very high but maximum reduction of bacterial load was seen in association to it.

\section{Discussion}

The papillary structure of the dorsum of the tongue forms a distinctive ecological niche that provides an adequate surface area favouring the acquisition of microorganisms and food debris. Tongue microorganisms may contribute to dental plaque formation. The present study showed highly significant reduction in aerobic and anaerobic bacterial load by all three aids except for the anaerobic bacterial load seen with brush tongue scrapper. When in-between comparison was done for the three aids, highly

Table 2: Differences in mean WTCI score among tongue cleaning aids

\begin{tabular}{llllll}
\hline & \multicolumn{3}{c}{ Mean + Sd } & & \\
\cline { 2 - 3 } Aids & Pre & Post & Mean + SD & p value & Significance \\
\hline WTCI-I (brush) & $5.55+2.73$ & $1.85+2.68$ & $3.70+2.68$ & $<.001$ & $\mathrm{~S}$ \\
$\begin{array}{l}\text { WTCI-II } \\
\text { (plastic scrapper) }\end{array}$ & $5.57+2.67$ & $2.90+1.73$ & $2.80+2.29$ & $<.001$ & HS \\
$\begin{array}{l}\text { WTCI-III (metal } \\
\text { scrapper) }\end{array}$ & $6.35+1.95$ & $3.35+1.96$ & $3.00+1.55$ & $<.001$ & $\mathrm{~S}$
\end{tabular}

Table 3: Differences in mean aerobic bacterial count among tongue cleaning aids

\begin{tabular}{llllll}
\hline & \multicolumn{2}{c}{ Mean + SD } & & \\
\cline { 2 - 3 } Aids & Pre & Post & Mean + SD & pvalue & Significance \\
\hline Brush scrapper & $448000+420697.83$ & $133750+64398.66$ & $314250.00+424815.47$ & $<0.05$ & S \\
Plastic scrapper & $2460000+682798.12$ & $263500+262417.10$ & $2196500+1711748$ & $<0.001$ & HS \\
Metal scrapper & $3140000+404550.43$ & $266000+255331.20$ & $2874000+1400526.33$ & $<0.001$ & HS \\
\hline
\end{tabular}

Table 4: Differences in mean anaerobic bacterial count among tongue cleaning aids

\begin{tabular}{llllll}
\hline & \multicolumn{2}{c}{ Mean + Sd } & Mean + SD & pvalue & Significance \\
\cline { 2 - 5 } AlDS & Pre & & Post & $>0.05$ & NS \\
Brush scrapper & $2525000+1417198.78$ & $2475000+1260506$ & $50000+1633248$ & $<0.001$ & HS \\
Plastic scrapper & $2205000+1016752.53$ & $294000+227319.16$ & $1911000+1036576$ & $<0.001$ & HS \\
Metal scrapper & $2155000+1016284.08$ & $260500+229553.40$ & $1894500+1017509$ & $<0$ \\
\hline
\end{tabular}


Effectiveness of Various Tongue Cleaning Aids

Table 5: Differences in mean value of bacterial load among tongue cleaning aids

\begin{tabular}{|c|c|c|c|c|c|c|}
\hline & & \multicolumn{2}{|c|}{ Mean \pm standard deviation } & \multirow{2}{*}{$\begin{array}{l}\text { Mean } \pm \text { standard } \\
\text { deviation }\end{array}$} & \multirow[b]{2}{*}{$p$ value } & \multirow[b]{2}{*}{ Significant } \\
\hline & & Pre & Post & & & \\
\hline \multirow[t]{2}{*}{ Brush scrapper } & Anaerobic & $252500 \pm 1417198.78$ & $2475000 \pm 1260506$ & $50000 \pm 1633248$ & $>.05$ & NS \\
\hline & Aerobic & $448000 \pm 420697.83$ & $133750.00 \pm 64398.66$ & $314250.00 \pm 24815.50$ & $<0.001$ & HS \\
\hline \multirow[t]{2}{*}{ Plastic scrapper } & Anaerobic & $2205000.00 \pm 1016752.53$ & $29400 \pm 227319.16$ & $19110000 \pm 1036576$ & $<0.001$ & HS \\
\hline & Aerobic & $2460000 \pm 1682798.12$ & $263500 \pm 262417.10$ & $2196500 \pm 1711748$ & $<0.001$ & HS \\
\hline \multirow[t]{2}{*}{ Metal scapper } & Anaerobic & $2155000 \pm 1016284.08$ & $260500 \pm 2293553.40$ & $1894500 \pm 1017509$ & $<0.001$ & HS \\
\hline & Aerobic & $3140000 \pm 1404550.43$ & $2660000 \pm 255331.20$ & $2874000 \pm 14000526.33$ & $<0.001$ & HS \\
\hline
\end{tabular}

Table 5(A): Comparison of mean values of bacterial load reduction among tongue cleaning aids

\begin{tabular}{lllll}
\hline & Mean \pm standard deviation & Pvalue & Significant \\
\hline Bnaerobic & Brush scrapper & Plastic scrapper & & \\
Aerobic & $50000 \pm 1633248$ & $19110000 \pm 1036576$ & $<0.001$ & HS \\
\hline \multicolumn{7}{c}{ Brush scrapper } & Metal scrapper & HS & \\
\hline Anaerobic & $50000 \pm 1633248$ & $1894500 \pm 1017509$ & $<0.001$ & HS \\
Aerobic & $314250.00 \pm 24815.50$ & $2874000 \pm 14000526.33$ & $>.0 .05$ & NS \\
\hline Anaerobic & Plastic scrapper & Metal scrapper & & NS \\
Aerobic & $19110000 \pm 1036576$ & $1894500 \pm 1017509$ & $>.0 .05$ & NS \\
\hline
\end{tabular}

Table 6: Percentage distribution of response regarding acceptability of each tongue cleaning aid

\begin{tabular}{llll}
\hline Response & Brush tongue cleaner & Plastic tongue cleaner & Metal tongue cleaner \\
\hline Difference in level of halitosis (\%) & $16(80 \%)$ & $16(80 \%)$ & $2(10 \%)$ \\
Taste alteration (\%) & $2(10.00)$ & $2(50.00)$ & $9(45.00)$ \\
Gagging reflex (\%) & $9(45 \%)$ & $13(65 \%)$ & $1(5 \%)$ \\
Uncomfortable (\%) & $1(5 \%)$ & $12(60 \%)$ & $16(80 \%)$ \\
\hline
\end{tabular}

significant reduction was observed with the plastic tongue scrapper. The results of the present study were similar to the studies conducted by Menon and Coykendall ${ }^{8}$ and Quirynen et al. ${ }^{9,10}$ which also demonstrated a minor change in bacterial count after tongue cleaning.

The impact of surface roughness increased the bacterial count on the dorsum of the tongue. Luciana ${ }^{11}$ observed that there was a reduction of the total number of colony forming units when tooth brushing and tongue cleaning were performed. Counting of salivary bacteria for evaluation of mechanical methods of tongue cleaning has been justified since the removal of bacterial niches, as those present on tongue surface, contributes to reduce the total number of bacteria of oral cavity.

The surface characteristics of the dorsum of the tongue are mainly responsible to cause difficulty in removing its bacterial load. According to Collins and Dawes, ${ }^{12,13}$ the dorsal mucosa of the tongue has an approximate area of $25 \mathrm{~cm}^{2}$ which possesses very irregular surface topography. The posterior surface exhibits a variety of oval crypto lymphatic units which provides roughness to this area. The anterior portion is more rough due to presence of numerous number and variety of papillae. This comprised of fungiform papillae with average length of $0.5-0.8 \mathrm{~mm}$, filiform papillae with its $0.5 \mathrm{~mm}$ core, foliate papillae situated at the edge of the tongue, vallate papille with $2-3 \mathrm{~mm}$ diameter and $1 \mathrm{~mm}$ height and central crater with uplifted borders. These numerous depressions situated on the tongue act as perfect niches for bacterial attachment and growth and also provide shelter against various cleaning actions.

The mean value of tongue coating obtained by WTCI showed a reduction with all three aids although highly significant reduction was seen with plastic tongue scraper. An approximately $55 \%$ reduction of tongue coating was seen with plastic tongue scraper in the post-intervention results. The rough surface of the plastic scraper helps to remove the tongue coating by penetrating deep into the muscular folds of tongue. Arthur et al. ${ }^{14}$ concluded additive effects of mechanical and chemical tongue cleaning aids showed higher reduction as compared to the present study i.e. $74 \%$ reduction was seen on tongue coating.

Winkler et al. ${ }^{15}$ revealed that tongue brushing can increase the taste recognition in old age adults (especially those wearing a denture) by eliminating the thick bacterial coating present on the tongue. The subjective evaluation of the instruments used slightly increases in taste recognition for all flavor whereas the chief complaint of the study subjects was related to gagging reflex. More than three fourth of the subjects complained of gag reflex with the plastic tongue cleaner, this might be a major cause of dissatisfaction regarding tongue-cleaning aids. Rowley et al. ${ }^{16}$ and Christensen ${ }^{17}$ stated that most of the people use toothbrush to clean their tongue because it does not require any additional tool. Although on contrary 
on the basis of the present study it is not the most effective way of reducing tongue coating and bacterial load. The major drawback of the study was that sample size was small and the study design was not crossover. To have an actual broader view of the effectiveness of various other commercially available tongue cleaners; larger study with long duration and with higher sample size is advised.

\section{ConcLusion}

Finally, the data obtained by the study indicate that the use of a tongue cleaner plays an important role in controlling bacterial load and count. However, out of the three the most effective reduction of the bacterial count was observed with the plastic tongue cleaner. Although, the market is exploded with other types and brands of tongue cleaning aids, more such further research is required to conclude the best out of all.

\section{Clinical significance}

Due to significant mechanical effectiveness demonstrated by both plastic and metal tongue scrappers in reducing tongue coating and bacterial load; the results of the present study may be helpful for the dentists while prescribing tongue cleaners to their patients in their clinical practice.

\section{References}

1. Kazor CE, Mitchell PM, Lee AM, et al. Diversity of bacterial populations on the tongue dorsa of patients with halitosis and healthy patients. J Clin Microbiol 2003;41:558-563.

2. Tonzetich J, Ng SK. Reduction of malodor by oral cleansing procedures. Oral Surg Oral Med Oral Pathol 1976;42(2):172-181.

3. Loesche WJ. The effects of antimicrobial mouth rinses on oral malodor and their status relative of U.S. Food and Drug Administration regulations. Quintessence Int 1999;30:311-318.
4. De Boever EH, Loesche WJ. Assessing the contribution of anaerobic microflora of the tongue to oral malodor. J Am Dent Assoc 1995;126(10):1384-1393.

5. Hinode D, Fukui M, Yokoyama N, et al. Relationship between tongue coating and secretory-immunoglobulin a level in saliva obtained from patients complaining of oral malodor. Clin Periodontol 2003;30(12):1017-23.

6. Loesche WJ, Kazor CE. Microbiology and treatment of halitosis. Periodontol 2000 2002;28:256-279.

7. Winkel EG, Roldán S, Van Winkelhoff AJ, et al. Clinical effects of a new mouthrinse containing chlorhexidine, cetylpyridinium chloride and zinc-lactate on oral halitosis. A dual-center, double-blind placebo controlled study. J Clin Periodontol 2003;30(4):300-307.

8. Menon MV, Coykendall AL. Effect of tongue scraping. J Dent Res 1994;73(9):1492.

9. Quirynen M, Avontroodt P, Soers C, et al. Impact of tongue cleansers on microbial load and taste. J Clin Periodontol 2004;31:506-510.

10. Quirynen M, Zhao H, van Steenberghe D. Review of the treatment strategies for oral malodour. Clin Oral Investig 2002;6(1):1-10.

11. Casemiro LA, Martins CHG, De Carvalho TC, et al. Effectiveness of a new toothbrush design versus a conventional tongue scraper in improving breath odor and reducing tongue microbiota. J Appl Oral Sci 2008;16(4):271-274.

12. Collins LMC, Dawes $C$. The surface area of the adult human mouth and thickness of the salivary film covering the teeth and oral mucosa. J Dent Res 1987;66:1300-1302.

13. Dawes C. Salivary flow patterns and the health of hard and soft oral tissues. J Am Dent Assoc 2008;(Suppl)139:18S-24S.

14. Arthur G, Barnes GP, Thaye. Effects of Tongue Brushing on Tongue Coating and Dental Plaque Scores. J Dent Res 1997;54:6-10.

15. Winkler S, Garg AK, Mekayarajjananonth T, et al. Depressed taste and smell in geriatric patients. J Am Dent Assoc 1999;130(12):1759-1765.

16. Rowley EJ, Schuchman, LC, Tishk MN, et al. Tongue brushing versus tongue scraping: a comparison of plaque re-accumulation, gingivitis and patient acceptance. Clin Prev Dent 1987;9:13-16.

17. Christensen GJ. Why clean your tongue? J Am Dent Asso 1998;129:1605-1607. 